\title{
Hope and Its Relation to Suicidal Risk Behaviors among Malaysian Adolescents
}

\author{
Choon Min Wai ${ }^{1}$, Mansor Abu Talib ${ }^{1}$, Siti Nor Yaacob ${ }^{1}$, Tan Jo-Pei ${ }^{1}$, Hamidin Awang ${ }^{2}$, Sallahuddin Hassan ${ }^{3}$ \& \\ Zanariah Ismail $^{1}$ \\ ${ }^{1}$ Faculty of Human Ecology, Universiti Putra Malaysia, Malaysia \\ ${ }^{2}$ Faculty of Medicine and Health Science, Universiti Putra Malaysia, Malaysia \\ ${ }^{3}$ School of Economics, Finance and Banking, UUM College of Business, Universiti Utara Malaysia, Malaysia \\ Correspondence: Choon Min Wai, Department of Human Development and Family Studies, Faculty of Human \\ Ecology, Universiti Putra Malaysia, 43400 Sri Kembangan, Selangor Darul Ehsan, Malaysia. Tel: \\ 60-16-680-7279. E-mail:minwai_choon@hotmail.com
}

Received: January 24, 2014 Accepted: March 19, 2014 Online Published: May 26, 2014

doi:10.5539/ass.v10n12p67 URL: http://dx.doi.org/10.5539/ass.v10n12p67

\begin{abstract}
Suicide is an epidemic issue worldwide and Asian countries are of no exception. In Malaysia, adolescent suicide constituted $10 \%$ of the overall reported suicide cases. Aforementioned, the current study examines Snyder's theory of hope to understand suicidal risk among Malaysian adolescents. A total of 1441 adolescents were recruited using a multistage cluster sampling. Results showed significant relationship between both agency and pathway thinking with risk of suicidal behavior. Specifically, only agency thinking uniquely predicts adolescents' suicidal risk in a regression model. Adolescents with higher motivation towards accomplishing a goal or plan have lower risk engaging in suicidal behaviors. Thus, suicide prevention focusing on increasing hope is significantly important. Limitations were discussed in the study.
\end{abstract}

Keyword: suicidal risk, hope, agency, pathway, adolescent

\section{Introduction}

Suicide has been a distressing phenomenon which affects nearly one million people yearly across the globe (World Health Organization [WHO], 2013). The tragic phenomenon is seen shifting to Asia which constituted approximately $60 \%$ of the world suicide solely in the region itself. In Malaysia, particularly, adolescent suicide constituted $10 \%$ of the overall reported suicide cases in which it ranked the top three causes of death in adolescent and young adult category (Hayati, Abdullah, \& Shah, 2008). Sudden reduction of adolescents and young adults in the country might influence and affect the human capital growth in such a way that affects country's productivity (Bronzini \& Piselli, 2008). Shockingly, the number of suicide death might be higher due to the nature of death recorded and under-reported suicide cases in the country (Sipalan, 2012).

Numerous theories have been constructed and discussed to understand suicide in depth (Durkheim, 1951; Joiner, 2005; Snyder, 2002). Specifically, Snyder (2002) has successfully proposed and elucidated his theory of hope in discussing suicidality. In his theory, he corroborated that hope includes detail trilogy-goals, pathway, and agency in which results in different consequences. Hope is a perception of attainable goals in which goals are reachable in both pathway and agentic thoughts (Snyder et al., 2000). In order to reach specific goals (either positive or negative consequences), Snyder believes one has to have a plan (pathway) with sensible amount of goal-directed energy (agency). Snyder further iterated that goal is a cognitive component of hope theory in which it provides the mental action sequences. In order to approach particular goal pursuits, Snyder believes that high hope individuals could generate alternate routes despite having a primary route in mind as compared to low hope individuals. In addition, agency thoughts are the motivational component in which it involves the mental energy to initiate and continue using a pathway to reach specific goals (Snyder, 2002).

A handful of studies have postulated that hope as being the protective factor of suicidality. More recently, Davidson and Wingate (2013) elucidated hope in predicting lower levels of suicidal risks specifically in a clinical sample. They found that hope only lowered one's level of burdensomeness and thwarted belongingness but not suicidal ideation. In addition, hope was also found to provide a protective influence against the effect of 
rumination in predicting suicidal ideation (Tucker et al., 2013). Tucker and colleagues have ascertained that individuals with goals are able to develop (pathway) and motivated (agency) to achieve those goals while less likely to ruminate their problems which in turn decreases the experience of depression and suicidal ideation when negative life events occur. In addition, hopeful individuals were less likely to experience suicidal behavior with increasing levels of depression (Hirsch, Visser, Chang, \& Jeglic, 2012). The latter however, postulated that Asian samples did not show significance in which hope buffers the association between depression and suicidal behavior due to a minute sample size. Besides that, Chang, Yu, Kahle, Jeglic, and Hirsch (2013) have also successfully postulated that hope lowers the risk of suicidal risks (hopelessness and suicidal behavior) while accounting for a significant amounts of variance in suicidal risk in a Latino student sample. However, the latter suggested future studies to clarify the status of hope as potential predictor of suicidal risk in other ethnic or race groups.

As such, the present study aims to investigate the relationship between hope and the risk of suicidal behaviors among school-based adolescents in Malaysia. Besides that, constructs of hope theory (pathway and agency thinking) are being investigated to uniquely predict suicidal risk behaviors among these adolescents. For the best interest of this study, Snyder's hope theory was discussed and evaluated empirically specifically in an Asian sample. As stated by Grewal and Porter (2007), empirical examination is warranted to test the assertions of hope theory for understanding suicide.

\section{Methods}

\subsection{Research Designs, Procedures, Participants, and Location}

The present research utilized a quantitative research approach with cross-sectional survey method. A multistage cluster sampling was utilized in which the researchers successfully collected questionnaires across twenty (20) local secondary schools across five (5) different states (Pulau Pinang, Terengganu, Selangor, Johor, and Sarawak) in Malaysia.

Research proposal and sample of self-administered questionnaires were initially submitted to the Ministry of Education Malaysia, followed by respective State Department of Education and lastly to the principal of respective schools as part of approval seeking protocol. Upon receiving approvals from various levels, consent was then obtained from respective school principal to conduct the mentioned research in respective schools. Based on the education system practiced in Malaysia, parental consents were obligated to school principal on informed consents for all research related issues.

Subsequently, briefing and instructions were given by the researchers to the participants during one of the school period. Participants were then told to read and sign the research consent in which they agree. Hence, after screening of unwanted and incomplete data, a total number of 1441 participants were then included in further analyses.

\subsection{Measures}

\subsubsection{The Children's Hope Scale (CHS)}

The Children's Hope Scale (Snyder et al., 1997) measures goal-directed thinking according to Snyder's hope theory. It consists of a total of 6 items with 3 items related to pathway thinking (measures particular plan or goal pursuits with thoughts generating useful routes) and the remaining 3 items related to agency thinking (motivational aspect of one's capacity to reach desired goals or plans). Example of pathway items include, "I can think of many ways to get the things in life that are most important to me" and example of agency items include, "I think I'm doing pretty well". Each item consists of 6 Likert scales ranging from 1 (None of the time) to 6 (All of the time). Higher scores indicate hopefulness. The CHS has a relatively high reliability in the current study ( $\alpha$ $=.84$ ).

\subsubsection{Suicidal Behavior Questionnaire-Revised (SBQ-R)}

The SBQ-R (Osman et al., 2001) measures individuals' lifetime suicide thoughts and attempts, frequency of suicide ideation, threat of suicide attempt, and future likelihood of attempting suicide. Each item consists of different Likert scales with item 1 (Have you ever thought about or attempted to kill yourself?) ranging from 1 (Never) to 4 (I have attempted to kill myself, and really hoped to die), Item 2 (How often have you thought about killing yourself in the past year?) ranging from 1 (Never) to 5 (Very Often), Item 3 (Have you ever told someone that you were going to commit suicide, or that you might do it?) ranging from 1 (No) to 3 (Yes, more than once, and really wanted to do it), and Item 4 (How likely is it that you will attempt suicide someday?) ranging from 0 (Never) to 6 (Very Likely). Higher scores indicate adolescents in greater risk of engaging in suicidal behavior. Reliability estimate obtained in the present study was relatively high $(\alpha=.74)$. 


\section{Result}

Table 1. Inter-correlations, means, and standard deviations for all study variables

\begin{tabular}{lllllll}
\hline & $M$ & $S D$ & 1 & 2 & 3 & 4 \\
\hline 1. CHS & 22.41 & 6.64 & - & & & \\
2. Agency thinking & 11.06 & 3.58 & $.92^{* *}$ & - & $.71^{* *}$ & - \\
3. Pathway thinking & 11.35 & 3.60 & $.93^{* *}$ & $-.13^{* *}$ & $-.09^{* *}$ & - \\
4. SBQ-R & 2.13 & 0.52 & $-.12^{* *}$ & -.13 & \\
\hline
\end{tabular}

Note: $\mathrm{CHS}=$ Children's Hope Scale, SBQ-R $=$ Suicidal Behavior Questionnaire-Revised, ${ }^{* *} p<0.001$

Pearson correlation analysis was performed to test the relationship between hope, agency thinking, pathway thinking, and risk of suicidal behaviour (refer to Table 1). The result of correlation shown that there was a negative significant relationship between hope and suicidal risk, $r(1441)=-.12, p<.001$. The result suggested that hopeful adolescents have lower risk of engaging in suicidal behavior. Specifically, both agency thinking, $r$ $(1441)=-.13, p<.001$ and pathway thinking, $r(1441)=-.09, p<.001$ were found to be negatively correlated with suicidal risk. Results of the inter-correlations are illustrated in Table 1.

Table 2. Agency thinking and pathway thinking as predictors of suicidal risk

\begin{tabular}{lllll}
\hline Predictors & B & SEB & $\boldsymbol{\beta}$ & $\boldsymbol{t}$ \\
\hline Constant & 2.33 & .05 & & $-13^{* * *}$ \\
Agency & -.02 & .005 & .41 \\
Pathway & .00 & .005 & .002 (n. s) & .06 \\
\hline
\end{tabular}

Note: $\mathrm{R}=0.13, \mathrm{R}^{2}=0.02$, Adj. $\mathrm{R}^{2}=0.01,{ }^{* * *} \mathrm{p}<.000, \mathrm{n} . \mathrm{s}=$ non-significant

Multiple regression analyses revealed that only agency thinking $(\beta=-0.13, \mathrm{p}=0.001)$ uniquely predict suicidal risk. Conversely, pathway thinking does not significantly predict suicidal risk $(\beta=0.002, \mathrm{p}>.05)$. As such, only a minute amount of variance of about $2 \%$ of the suicidal risk is explained by agency thinking. Summarized results were shown in Table 2 respectively.

\section{Discussion}

It was widely acknowledged that hope theory was operationalized and discussed empirically on suicidality across literatures (Davidson et al., 2009; Davidson \& Wingate, 2013; Grewal \& Porter, 2007; Snyder, 2002). The current study successfully posited a significant negative relationship between hope (agency and pathway thinking) and suicidal risk behaviour. Results indicated that adolescents who are hopeful have a lowered risk of engaging in suicidal behaviour. As evident in Turner (2005), hope acted as a driving force (passion, energy, and drive) and a knowing that things would go well in life for participants to achieve specific goals. Generally, hope gives individuals a push and determination to achieve particular goals in life while protecting one to engage in destructive behaviors.

Interestingly, when both the constructs were entered into the same hierarchical regression equations predicting suicidal risk behavior, agency thoughts remained significant while pathway thoughts did not. This may suggest that agency thought is a more prominent protective factor against suicidal risk behaviour as compared to pathway thoughts. Evidently, Tong, Fredrickson, Chang, and Lim (2010) asserted in their study in which hope is only associated with agency thinking and not with pathways thinking. The study iterated that pathway thoughts are not as important as agency thoughts in reaching a specific goal. Specifically, they addressed individuals who feel that as long as specific goals can be attained (agentic), regardless of seeing themselves to be able to generate plans or strategies (pathway), they remained to be hopeful (Tong et al., 2010). Thus, it is imperative to reason the effect of agency thinking in reducing suicidal risk behavior.

As such, the implication of hope in the realm of suicide prevention, attention should be emphasized on instilling hope in an approach to reduce incidence of suicidal behavior among adolescents. Specifically, Kondrat and Teater (2010) suggested solution-focused therapy as an approach to increase one's hopefulness specifically to those who were admitted to the ER with suicidal ideation. The mentioned therapy serves as an avenue in 
assessing suicidal risk and simultaneously serves as an opportunity to increase one's hope. Besides that, Snyder et al. (2000) believed on the importance of cognitive-behavioral interventions in generating hope during sessions of psychotherapies. Such interventions may help to reduce adverse incidence by emphasizing goal setting, strategy development, and even alteration of negative beliefs regarding goal attainment (Snyder et al., 2000). This is particularly true, specifically, as reviewed by Gillham and Reivich (2004), they elucidated the importance of cognitive-behavioral therapies in identifying negative beliefs, evaluate and generate alternatives which are more hopeful as a strategy to promote hope in adolescents.

\subsection{Limitations and Conclusion}

The current study does have its limitations. Since the study was a cross-sectional, the study could not establish causal relationships and is not possible to determine whether hope serves as a protective factor towards suicidal behavior. Longitudinal studies are required to determine the cause and effect of hope specifically on suicidal behaviors. In addition, the generalization of the study is only limited to school-based adolescents. It is possible that the results would differ with the inclusion of dropouts and working adolescents, and specifically if the study is conducted in a clinical setting. Furthermore, inclusion of other potential variables such as optimism and religiosity in the study of suicidal behavior is necessary to determine the extent of hope in the association with suicidal risk behavior.

Despite the limitations, the current study has successfully examined the usage of Children's Hope Scale (CHS) in predicting suicidal risk behavior among adolescents. As to the authors' knowledge, the mentioned scale has yet to be used in examining suicidal risk as compared to other scales such as the Trait Hope scale, Revised Trait Hope scale and State Hope scale (Davidson et al., 2009; Davidson \& Wingate, 2013; Hirsch et al., 2012). Besides that, Snyder's hope theory was empirically proven in the local context especially in a positive psychology perspective. However, the aforementioned theory would need more affirmation and future testing as to how such variables interact in Asian samples.

\section{References}

Bronzini, R., \& Piselli, P. (2008). Determinants of long-run regional productivity with geographical spillovers: The role of R\&D, human capital and public infrastructure. Regional Science and Urban Economics, 39, 187-199. http://dx.doi.org/10.1016/j.regsciurbeco.2008.07.002

Chang, E. C., Yu, E. A., Kahle, E. R., Jeglic, E. L., \& Hirsch, J. K. (2013). Is doubling up on positive future cognitions associated with lower suicidal risk in Latinos? A look at hope and positive problem orientation. Cogn Ther Res, 37, 1285-1293. http://dx.doi.org/10.1007/s10608-013-9572-x

Davidson, C. L., \& Wingate, L. R. (2013). The glass half-full or a hopeful outlook: Which explains more variance in interpersonal suicide risk in a psychotherapy clinic sample? The Journal of Positive Psychology, 8(3), 263-272. http://dx.doi.org/10.1080/17439760.2013.787446

Davidson, C. L., Wingate, L. R., Rasmussen, K. A., \& Slish, M. L. (2009). Hope as a predictor of interpersonal suicide risk. Suicide and Life-Threatening Behavior, 39(5), 499-507. http://dx.doi.org/10.1521/ suli.2009.39.5.499

Donaldson, D., Spirito, A., \& Farnett, E. (2000). The role of perfectionism and depressive cognitions in understanding the hopelessness experienced by adolescent suicide attempters. Child Psychiatry and Human Development, 31(2), 99-111. http://dx.doi.org/10.1023/A:1001978625339

Durkheim, E. (1951). In J. A. Spalding, \& T. G. Simpson (Eds.), Suicide: A study in sociology. New York: Free Press. (Original work published 1897).

Durrant, T., Mercy, J., Kresnow, M., Simon, T., \& Potter, L. (2006). Racial differences in hopelessness as a risk factor for a nearly lethal suicide attempt. Journal of Black Psychology, 32(3), 285-302. http://dx.doi.org/ $10.1177 / 0095798406290468$

Gillham, J., \& Reivich, K. (2004). Cultivating optimism in childhood and adolescence. The ANNALS of the American Academy of Political and Social Science, 591, 146-163. http://dx.doi.org/10.1177/ 0002716203260095

Grewal, P. K., \& Porter, J. E. (2007). Hope theory: A framework for understanding suicidal action. Death Studies, 31, 131-154. http://dx.doi.org/10.1080/07481180601100491

Hadley, S. A., \& MacLeod, A. K. (2010). Conditional goal-setting, personal goals and hopelessness about the future. Cognition and Emotion, 24(7), 1191-1198. http://dx.doi.org/10.1080/02699930903122521 
Hayati, A. N., Abdullah, A. A., \& Shah, M. M. (2008). National Suicide Registry Malaysia: Pleminary report July-Dec 2007. Retrieved from http://www.crc.gov.my/documents/report/nsrm.pdf

Hirsch, J. K., Visser, P. L., Chang, E. C., \& Jeglic, E. L. (2012). Race and ethnic differences in hope and hopelessness as moderators of the association between depressive symptoms and suicidal behavior. Journal of American College Health, 60(2), 115-125. http://dx.doi.org/10.1080/07448481.2011.567402

Joiner, T. E. (2005). Why people die by suicide. Cambridge, MA: Harvard University Press.

Kondrat, D. C., \& Teater, B. (2010). Solution-focused therapy in an Emergency Room setting: Increasing hope in persons presenting with suicidal ideation. Journal of Social Work, 12(1), 3-15. http://dx.doi.org/10.1177/ 1468017310379756

Kuo, W. H., Gallo, J. J., \& Eaton, W. W. (2004). Hopelessness, depression, substance disorder, and suicidality. A 13-year community-based study. Soc. Psychiatry Psychiatr Epidemiol, 39, 497-501. http://dx.doi.org/ 10.1007/s00127-004-0775-z

Page, R. M., Yanagishita, J., Suwanteerangkul, J., Zarco, E. P., Mei-Lee, C., \& Miao, N. F. (2006). Hopelessness and loneliness among suicide attempters in school-based samples of Taiwanese, Philippine and Thai adolescents. School Psychology International, 27, 583-598. http://dx.doi.org/10.1177/0143034306073415

Sipalan, J. (2012, June 5). Suicide rate on the rise in Malaysia. The Star. Retrieved from http://www.thestar.com.my/News/Nation/2012/06/05/Suicide-rate-on-the-rise-in-Malaysia.aspx/

Snyder, C. R. (2002). Hope theory: Rainbows in the mind. Psychological Inquiry, 13(4), 249-275. http://dx.doi.org/10.1207/S15327965PLI1304_01

Snyder, C. R., Hardi, S. S., Cheavens, J., Michael, S. T., Yamhure, L., \& Sympson, S. (2000). The role of hope in cognitive-behavior therapies. Cognitive Therapy and Research, 24(6), 747-762. http://dx.doi.org/10.1023/ A:1005547730153

Tong, E. M. W., Fredrickson, B. L., Chang, W., \& Lim, Z. X. (2010). Re-examining hope: The roles of agency thinking and pathways thinking. Cognition and Emotion, 24(7), 1207-1215. http://dx.doi.org/10.1080/ 02699930903138865

Tucker, R. P., Wingate, L. R., O'Keefe, V. M., Mills, A. C., Rasmussen, K., Davidson, C. L., \& Grant, D. M. (2013). Rumination and suicidal ideation: The moderating roles of hope and optimism. Personality and Individual Differences, 55, 606-611. http://dx.doi.org/10.1016/j.paid.2013.05.013

Turner, D. S. (2005). Hope seen through the eyes of 10 Australian young people. Journal of Advanced Nursing, 52(5), 508-517. http://dx.doi.org/10.1111/j.1365-2648.2005.03619.x

\section{Copyrights}

Copyright for this article is retained by the author(s), with first publication rights granted to the journal.

This is an open-access article distributed under the terms and conditions of the Creative Commons Attribution license (http://creativecommons.org/licenses/by/3.0/). 